\title{
Influência da precipitação na qualidade da água do Rio Purus
}

\author{
Ana Elisa Pereira SILVA ${ }^{1}$, Carlos Frederico ANGELIS ${ }^{1}$, Luiz Augusto Toledo MACHADO ${ }^{1}$, \\ Andrea Viviana WAICHAMAN ${ }^{2}$ \\ RESUMO
}

Os impactos da precipitação na qualidade da água ao longo do rio Purus, localizado no estado do Amazonas, foi investigado por meio de dados de precipitação, estimada por satélites, e informações sobre a temperatura da água, condutividade, $\mathrm{pH}$, turbidez, oxigênio dissolvido e sólidos suspensos totais, adquiridas em quatro diferentes áreas ao longo do rio. Os resultados mostraram correlação negativa entre precipitação e turbidez e positiva entre precipitação e temperatura, condutividade, oxigênio dissolvido, sólidos suspensos totais e $\mathrm{pH}$. $\mathrm{O}$ uso do solo, juntamente com o regime de precipitação, parecem ser os fatores principais que determinam a qualidade da água nos pontos de amostragem.

PALAVRAS ChaVeS: qualidade da água, Rio Purus, precipitação, pH, condutividade.

\section{Impacts of precipitation on the water quality of the Purus River}

\section{ABSTRACT}

The impacts of precipitation on the water quality along the Purus River, located in the Brazilian State of the Amazonas, was investigated using data of precipitation estimated by satellite and information about water temperature, conductivity, $\mathrm{pH}$, turbidity, dissolved oxygen and total suspended solids. The data were acquired in four different areas along the river. The results showed negative correlation between precipitation and turbidity. They also showed positive correlation between precipitation and temperature, conductivity, dissolved oxygen, total suspended solids and $\mathrm{pH}$. The land use together with the rainfall regime seems to be the main sources of impact on the water quality around the sampling places.

KEY WORDS: water quality, Purus River, precipitation, $\mathrm{pH}$, conductivity.

1 Instituto Nacional de Pesquisas Espaciais, ana.silva@cptec.inpe.br, carlos.angelis@cptec.inpe.br, luiz.machado@cptec.inpe.br

2 Universidade Federal do Amazonas, awaichaman@ufam.edu.br 


\section{INTRODUÇÃO}

Para assegurar a vida aos habitantes dos rios e garantir a ingestão de uma substância que não seja nociva à saúde da população, a qualidade da água é avaliada pela análise de alguns parâmetros de características físicas, químicas e biológicas. Seis das principais variáveis que orientam os parâmetros físicoquímicos, de acordo com a Cetesb (2006), com a Resolução do Conselho Nacional do Meio Ambiente (Conama) 357/2005 e outros estudos, foram definidas da seguinte forma:

- Temperatura da água: desempenha um importante papel no controle de espécies aquáticas, podendo ser considerada uma das características mais importantes do meio aquático. Seu valor pode variar entre $0^{\circ} \mathrm{C}$ e $30^{\circ} \mathrm{C}$.

- $p H$ : influencia os ecossistemas aquáticos naturais devido a seus efeitos na fisiologia de diversas espécies. Para que se conserve a vida aquática, o $\mathrm{pH}$ ideal deve variar entre 6 e 9 (Esteves, 1998).

- Turbidez: é a medida da capacidade da água em dispersar a radiação solar. É expressa, entre outras unidades, por NTU (Nephelometric Turbidity Units) e sofre influência direta da presença de sólidos em suspensão, que impedem que o feixe de luz penetre na água, reduzindo a fotossíntese da vegetação submersa e algas (Tavares, 2005).

- Condutividade: é a medida da capacidade da água em conduzir corrente elétrica, cujos valores são expressos em micro Siemens $\left(\mu \mathrm{cm}^{-1}\right)$. É função da concentração de íons presente na água que possam conduzir esta corrente elétrica, mas seu valor, além de depender da temperatura, também difere para cada íon (Esteves, 1998).

- Oxigênio Dissolvido: o oxigênio é um elemento essencial no metabolismo dos seres aquáticos aeróbicos. Em águas correntes, sob circunstâncias normais, o conteúdo de oxigênio é alto e varia ao longo do rio, devido a alteraçôes em suas características ambientais e em conseqüência das condiçōes climáticas (Maier, 1987). Seu valor indicado não é inferior a 5mg/L (CONAMA 357/05).

- Sólidos em suspensão: todas as impurezas, com exceção dos gases dissolvidos, são considerados sólidos suspensos em corpos d'água. Altas concentrações de sólidos em suspensão reduzem a passagem de luz solar, afetam organismos bentônicos e desequilibram as cadeias tróficas (Tavares, 2005).

As variáveis descritas anteriormente, além de discriminar a qualidade dos rios, são as que mais são influenciadas pelas estaçōes do ano. Carvalho et al. (2000) verificaram a existência de uma significativa relação entre o aumento da temperatura da água e dos sólidos suspensos com a condutividade elétrica na água, que pode ocorrer a partir de reaçōes desencadeadas na fauna aquática frente ao aumento da temperatura. Maier (1987) verificou relação também entre temperatura e o teor de oxigênio dissolvido, este tende a diminuir pelo aquecimento durante o dia e aumentar pelo resfriamento no período noturno; além disso a fotossíntese da vegetação submersa também exerce grande influência na variação diurna do teor de oxigênio dissolvido.

Segundo Maier (1987) uma pequena diminuição no pH pode estar associado ao aumento no teor de matéria orgânica que leva a conseqüente queda na quantidade de oxigênio dissolvido disponível no corpo d'água. Para essa autora o $\mathrm{pH}$ nas águas dos rios brasileiros varia de neutro a ácido e pode se alterar ao longo do rio. Um exemplo dessa variação é o rio Amazonas que apresenta elevação gradativa do $\mathrm{pH} \quad 4,0$ atingindo o máximo de 7,8 praticamente em águas marinhas (Maier, 1987). Carvalho et al. (2000) afirmam que com o aumento das chuvas, o $\mathrm{pH}$ tende a subir e aproximar-se da neutralidade, pois ocorre maior diluição dos compostos dissolvidos e escoamento mais rápido. Isso é causado pelo aumento no volume de água que faz com que a acidez da água diminua. Esteves (1998) diz que na maioria das águas naturais o pH é influenciado pela concentração de $\mathrm{H}^{+}$originado da dissociação do ácido carbônico, que gera valores baixos de $\mathrm{pH}$, e das reaçôes de íons carbonato e bicarbonato com a molécula de água, que elevam os valores de $\mathrm{pH}$ para a faixa alcalina. Apesar de se inter-relacionarem as variáveis físico-químicas podem ser influenciadas do meio externo, como a ocorrência de precipitação.

Para Esteves (1998) a condutividade elétrica, que depende da composição iônica dos corpos d'água, pode ser influenciada, também pelo volume de chuvas. Com baixa precipitação e predominância de rochas magmáticas na bacia de drenagem, a composição da água é, geralmente, determinada por produtos de intemperismo destas rochas. Com alta pluviosidade e predominância de rochas sedimentares, a composição iônica da água é determinada pela composição das rochas. Como a chuva é o principal agente regulador dos cursos de água, espera-se que ela seja também uma importante variável a ser considerada em estudos envolvendo a qualidade da água de rios e tributários.

O regime de chuvas no Brasil apresenta sazonalidade marcante com estação seca e chuvosa em épocas diferentes do ano de acordo com a localização geográfica (Figueroa e Nobre, 1989). Além da variação mensal da chuva, seu ciclo diurno também varia espacialmente (Angelis et al., 2004) e isso pode afetar as concentrações das variáveis físico-químicas nos rios.

Em ambientes onde a ação antrópica é marcante, a qualidade da água é afetada não só por fatores naturais, mas também por impactos das atividades humanas. Um exemplo de ambiente considerado com baixo índice de antropismo é a Bacia do Rio Purus, localizada na porção centro oeste da Região Amazônica. Apesar de próximo à fronteira agrícola (grande responsável pela degradação da qualidade hídrica), 
que avança no sentido sudoeste da Amazônia, essa área ainda não apresenta muitos impactos decorrentes da conversão de florestas tropicais. A qualidade das águas do Rio Purus é monitorada regularmente pela Agência Nacional de Águas (ANA) em quatro diferentes localidades. O monitoramento é feito desde 1975 , porém a série temporal mais completa foi obtida para o período de 1998-2005. As variáveis monitoradas pela ANA ao longo do rio Purus são as seis descritas anteriormente, e serão analisadas nessa pesquisa juntamente com valores de precipitação mensal observada nas áreas próximas aos pontos de coleta de amostra de água.

Apesar de existir uma longa série de dados de qualidade da água e saber que a Bacia do Rio Purus é de importância estratégica para a região norte do país, nenhum estudo focando os impactos da precipitação na qualidade da água desse rio foi realizado. Diante disso, o objetivo desse trabalho é avaliar quantitativamente os impactos da precipitação observada por satélites na qualidade da água do Rio Purus, em seu trecho que corta o estado do Amazonas. Para este trabalho foram utilizados os dados coletados nos postos de observação monitorados pela Agência Nacional de Águas.

\section{ÁREA DE ESTUDO}

A Bacia do Rio Purus está localizada na porção sudoeste da Amazônia e tem o rio Purus como tributário principal. É uma bacia trans-fronteiriça cobrindo áreas do Amazonas, Acre e dos países vizinhos, Peru e Bolívia. A porção localizada no Amazonas, onde estão os pontos de coleta de água da ANA, é coberta por floresta primária nativa e apresenta longas áreas de inundação ao longo do curso meândrico do Rio Purus. Apesar de ser a principal fonte de pesca que abastece os mercados de Manaus, o rio apresenta baixo índice de antropismo, com reduzidas áreas de conversão de floresta nas áreas urbanas dos municípios como Lábrea (AM) e Boca do Acre (AC). A figura 1 mostra a localização do Rio Purus e os locais de amostragem de água.

\section{DADOS}

As informações de qualidade de água foram obtidas por amostras feitas durante o período de 1998-2005 para as variáveis de: temperatura da água, $\mathrm{pH}$, turbidez, condutividade elétrica, oxigênio dissolvido e sólidos em suspensão. Estas variáveis foram medidas com medidores portáteis para análise de multiparâmetros modelo Multi 340i fabricado pela empresa WTW. Esse equipamento é dedicado a medições com precisão e confiabilidade para uso em campo. Pelo menos três coletas por ano compóem as séries temporais de cada ponto amostrado. As informaçōes sobre os locais de coleta de água estão mostradas na tabela 1 .

Os dados de chuva usados nessa pesquisa foram obtidos a partir de estimativas feitas por meio de informações coletadas

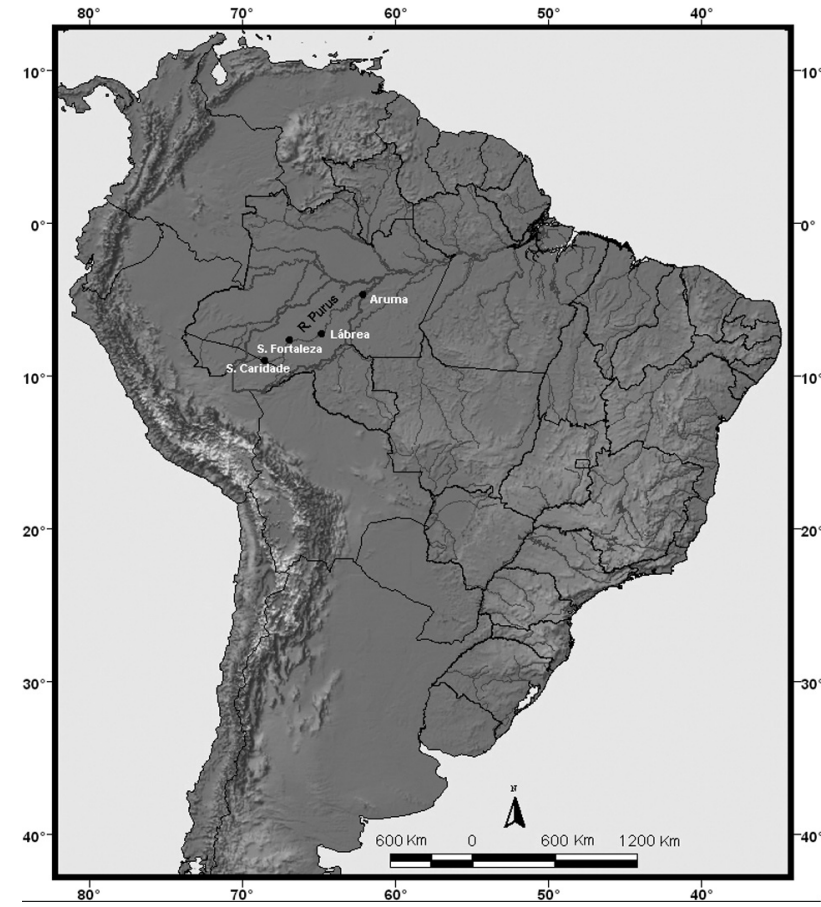

Figura 1 - Área de estudo e locais de amostragem de água

Tabela 1 - Coordenadas geográficas dos locais de coleta de amostras de água

\begin{tabular}{lll}
\hline Nome da Estação & Latitude (Sul) & Longitude (Oeste) \\
\hline Seringal da Caridade & $-09^{\circ} 02^{\prime} 06^{\prime \prime}$ & $-68^{\circ} 34^{\prime} 06^{\prime \prime}$ \\
Seringal Fortaleza & $-07^{\circ} 41^{\prime} 00^{\prime \prime}$ & $-66^{\circ} 56^{\prime} 00^{\prime \prime}$ \\
Lábrea & $-07^{\circ} 15^{\prime} 08^{\prime \prime}$ & $-64^{\circ} 48^{\prime} 00^{\prime \prime}$ \\
Arumã & $-04^{\circ} 41^{\prime} 00^{\prime \prime}$ & $-62^{\circ} 07^{\prime} 00^{\prime \prime}$ \\
\hline
\end{tabular}

pelos sensores do satélite TRMM (Tropical Rainfall Measuring Mission), que é equipado com um radar meteorológico, um sensor de microondas passivo e um sensor óptico no infravermelho (detalhes sobre o satélite e sensores podem ser encontrados em: http://trmm.gsfc.nasa.gov). Os dados de precipitação foram extraídos para o período de 1998-2005 nos mesmos locais de coleta de água. Foi utilizado dados mensais produzidos pelo algoritmo 3B43 que combina todos os sensores do TRMM com informaçōes de pluviômetros produzidas pelo Global Precipitation Climatology Center (GPCC). A saída dos dados 3B43 mostra o valor mensal da precipitação em cada ponto de grade cuja resolução espacial é de $0,25^{\circ} \times 0,25^{\circ}$. Mais detalhes sobre o algoritmo podem ser vistos em http://trmm.gsfc.nasa.gov/3b43.html.

\section{MÉTODOS}


A partir das informaçóes de chuva avaliada pelo satélite elaborou-se a climatologia mensal da precipitação observada durante o período de estudo. Os valores mensais de precipitação dos pontos de grade coincidentes com os locais de coleta de água foram inseridos na série temporal de qualidade da água. Para cada amostragem de água realizada em dias anteriores ao dia 15 associou-se o valor de chuva do mês anterior, enquanto que para leituras após o dia 15 foi associado o valor de precipitação do próprio mês da leitura.

Com o objetivo de eliminar os efeitos da sazonalidade da precipitação e seus impactos na qualidade da água na área de estudo, cada valor de precipitação descrito no parágrafo anterior foi subtraído pela média mensal obtida para todo o período de estudo. Isso foi feito por meio do cálculo do desvio da precipitação dado em $\mathrm{mm} / \mathrm{h}$ e expresso por:

Desvio = Precipitação mensal observada - Precipitação média mensal (1)

onde precipitação observada é o valor da chuva do mês da observação e precipitação média mensal é o valor médio mensal da precipitação obtido durante o período de estudo (1998 a 2005). Valores positivos (negativos) do Desvio para um dado mês significam que aquele mês registrou valores de precipitação acima (abaixo) da média observada durante o período de estudo.

\section{RESULTADOS}

\section{PRECIPITAÇÃO}

A climatologia da precipitação na bacia do rio Purus apresenta comportamento pluviométrico que evidencia ciclo anual marcado por estação chuvosa, que ocorre nos meses de Novembro a Março, e estação seca nos meses de Maio a Setembro. Os meses de Abril e Outubro são os de transição, e apresentam valores compatíveis com as estaçôes chuvosa e seca. Durante o período observado o ciclo anual da precipitação em cada local de amostragem de água seguiu o padrão típico mostrado na Figura 2.

O valor de precipitação acumulada mensal varia em cada local chegando a no máximo $550 \mathrm{~mm}$ em Março de $2003 \mathrm{em}$ Lábrea. Em 2005, que foi considerado um dos piores anos de seca em vários pontos da Amazônia, inclusive em localidades do rio Purus e Seringal da Caridade, apresentou em junho o menor acumulado mensal (12,68 mm). Em Seringal da Fortaleza, Lábrea e Arumã a precipitação atingiu em 2005 seu menor índice em julho com valores de $10,37 \mathrm{~mm}, 2,33$ mm e 43,38, respectivamente. A climatologia da precipitação observada nesse estudo está de acordo com trabalhos anteriores, como por exemplo, os de Figueroa e Nobre (1989).

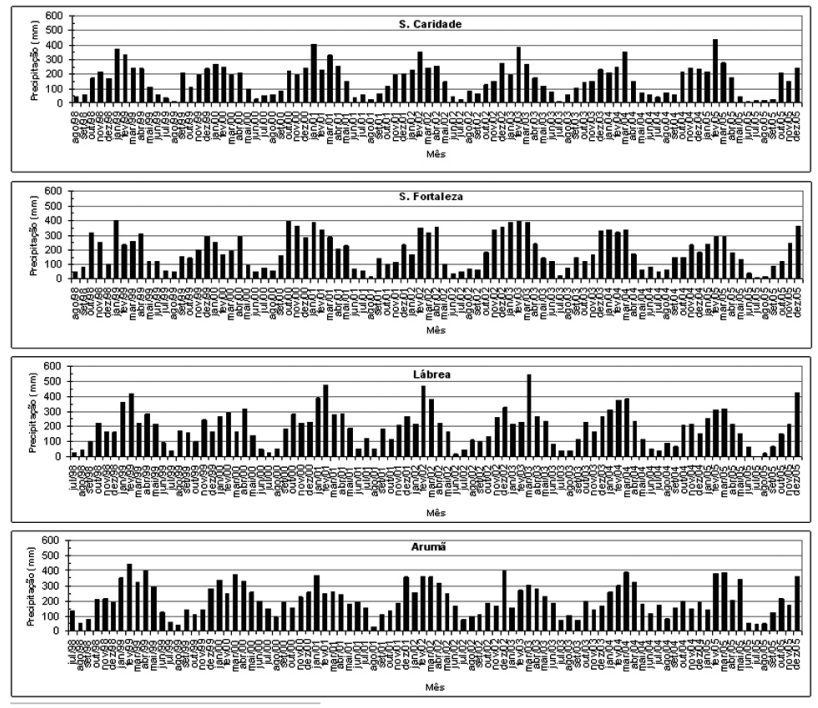

Figura 2 - Ciclo anual da precipitação para os locais de amostragem de água

\section{QUALIDADE DA ÁGUA}

O regime de chuva observado em cada localidade parece influenciar os valores de algumas das seis variáveis de qualidade de água amostrados, que também variam de acordo com a localidade. A correlação entre o valor do desvio da precipitação e as variáveis de qualidade de água foi significativa em metade das correlaçōes realizadas. As figuras 3, 4, 5 e 6 mostram as dispersões entre as seis variáveis analisadas em função da precipitação acumulada no mês da coleta da água, para cada localidade.

A temperatura da água e o oxigênio dissolvido tiveram maior correlação com a precipitação no Seringal da Caridade e esta foi a estação que apresentou correlaçôes com o maior número de variáveis. $\mathrm{O}$ aumento nos acumulados mensais de chuva parece diminuir a turbidez, correlação significativa entre essas duas variáveis ocorreu somente no Seringal da Caridade. De acordo com as figuras 3, 4, 5 e 6, a precipitação parece favorecer a diminuição da turbidez, enquanto contribui para aumento da temperatura, condutividade, sólidos em suspensão e oxigênio dissolvido. De montante (Seringal da Caridade) até jusante (Arumã), os valores de turbidez diminuíram em função da precipitação o que indica melhor correlação à jusante. Os sólidos em suspensão apresentaram maiores valores em Lábrea, influenciados positivamente pela precipitação. A correlação com a condutividade também indica diminuição (aumento) em função do aumento da precipitação em Seringal da Fortaleza e Lábrea (Seringal da Caridade e Arumã). O $\mathrm{pH}$ foi a variável que aumentou sua correlação positiva com a precipitação, do Seringal da Caridade (à montante) até Arumã (à jusante). 

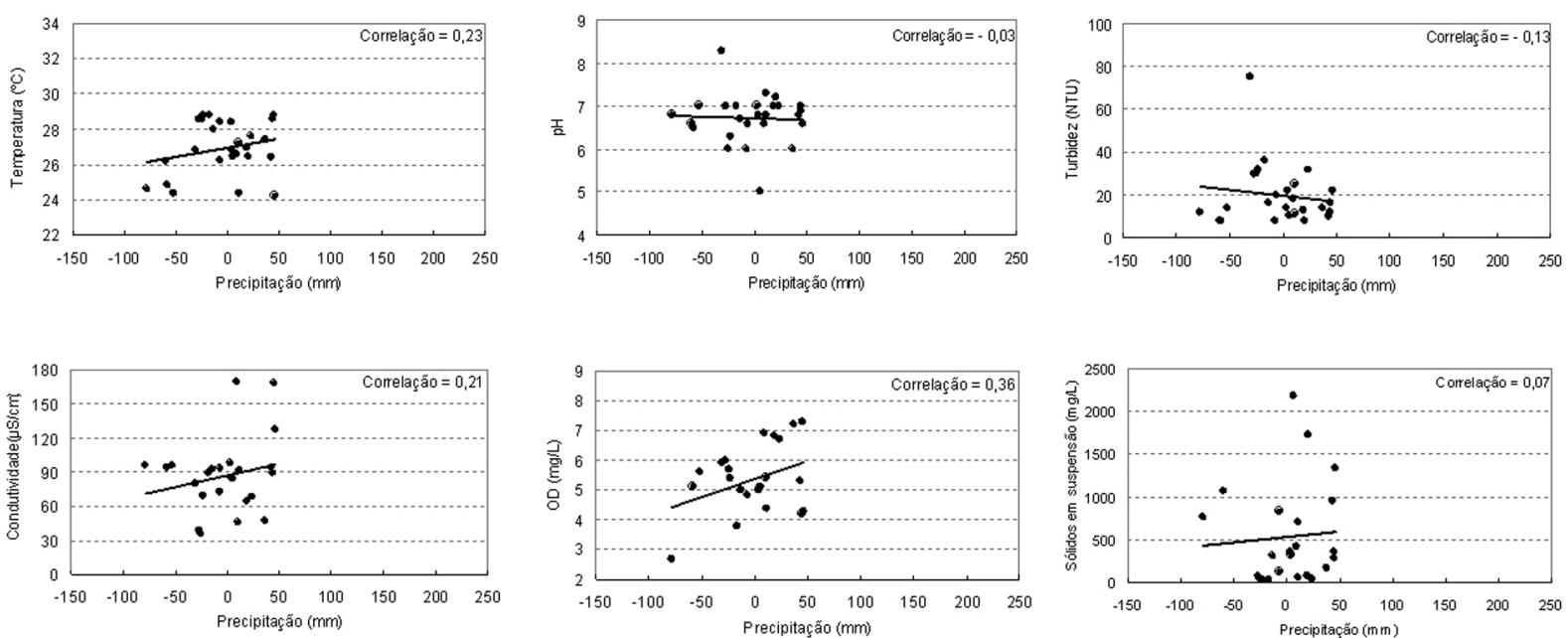

Figura 3 - Correlação entre as variáveis de qualidade de água e valor mensal de precipitação em Seringal da Caridade
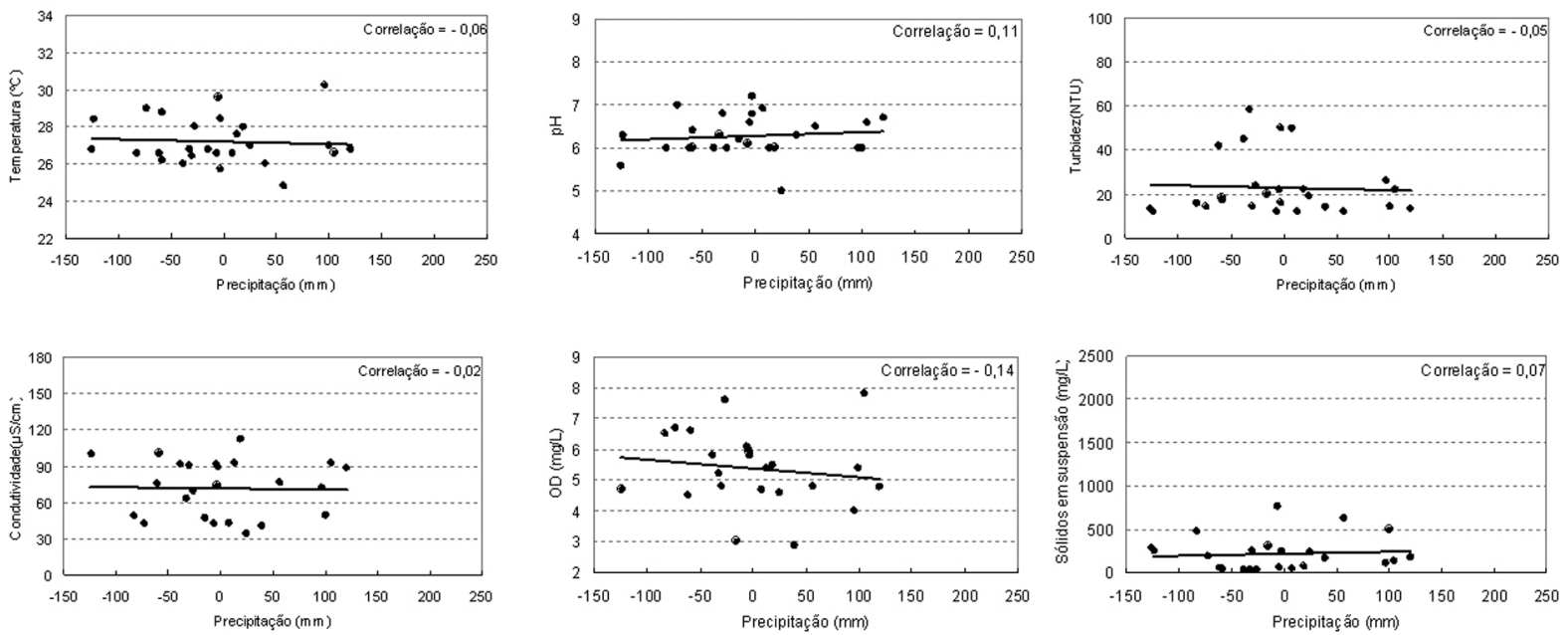

Figura 4 - Correlação entre as variáveis de qualidade de água e valor mensal de precipitação em Seringal da Fortaleza
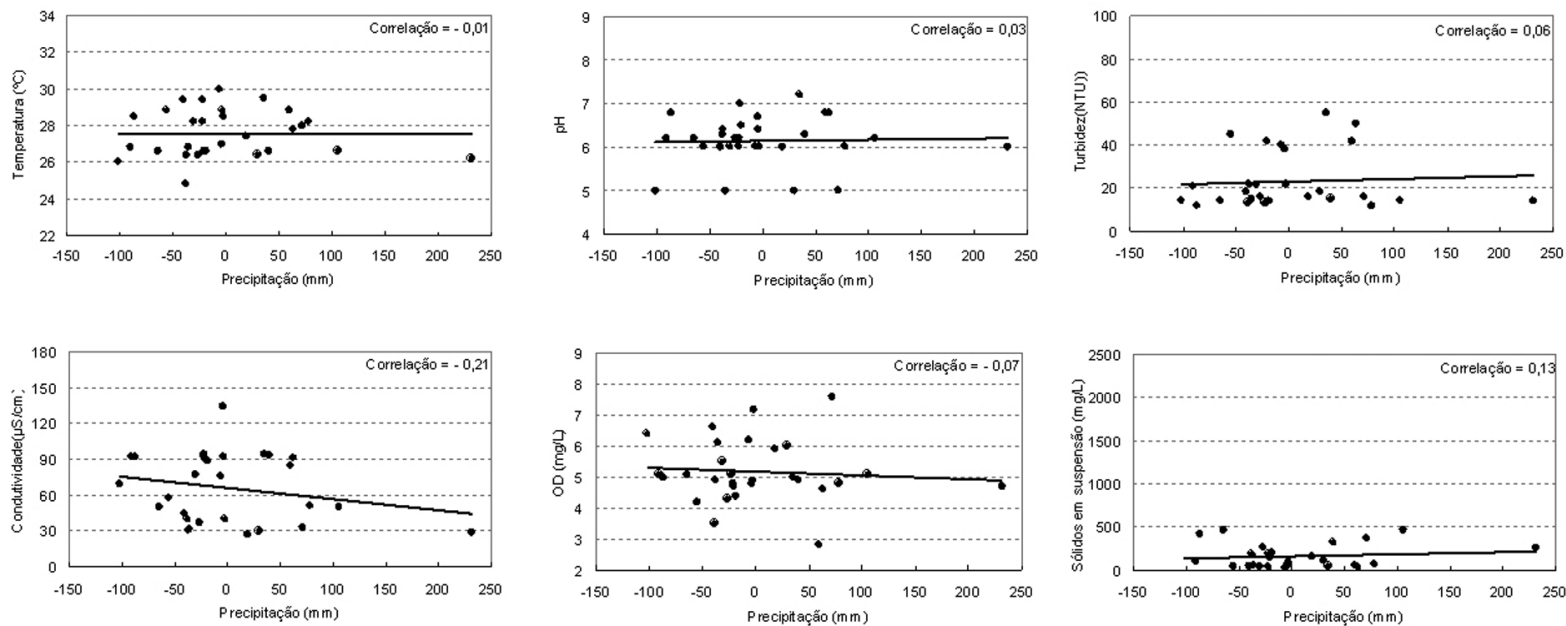

Figura 5 - Correlação entre as variáveis de qualidade de água e valor mensal de precipitação em Lábrea 

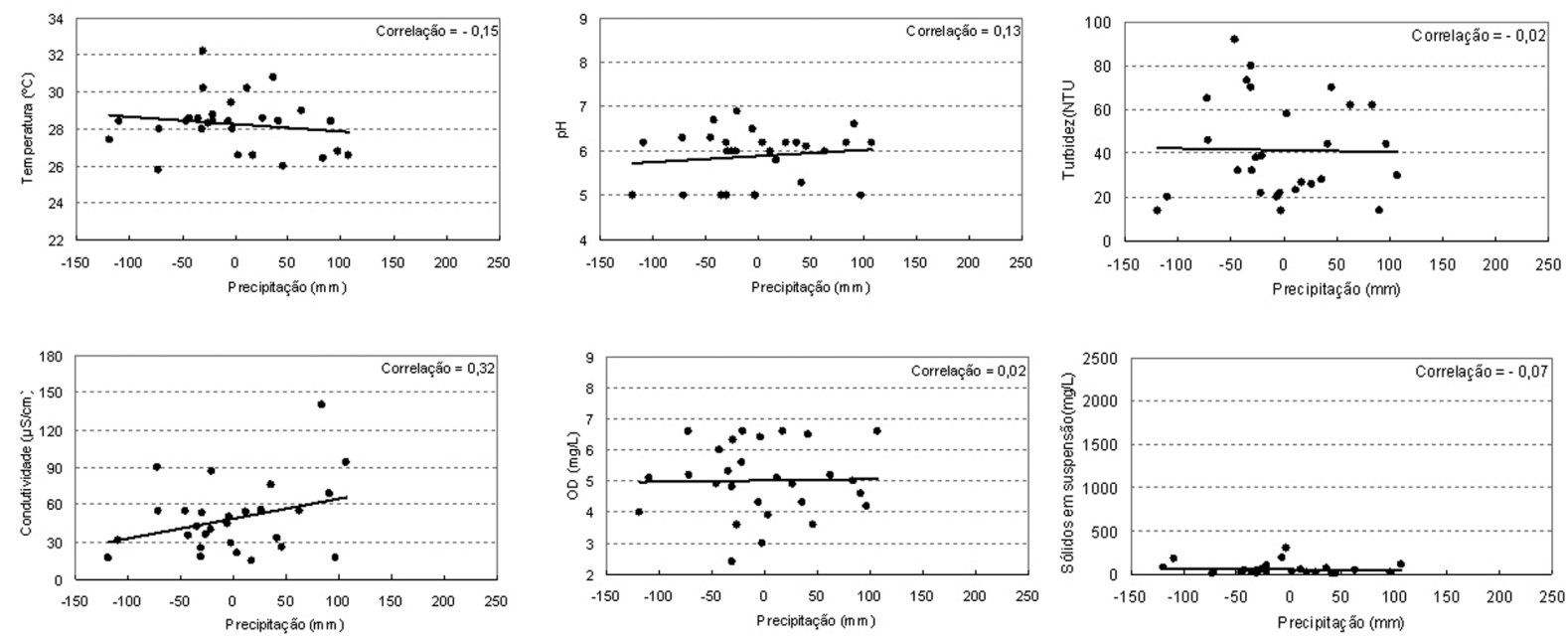

Figura 6 - Correlação entre as variáveis de qualidade de água e valor mensal de precipitação em Arumã

As séries temporais dos valores de cada variável da qualidade da água nas quatro localidades estudadas apresentam nítidas variaçōes ao longo do período de estudo. A figura 7 mostra os

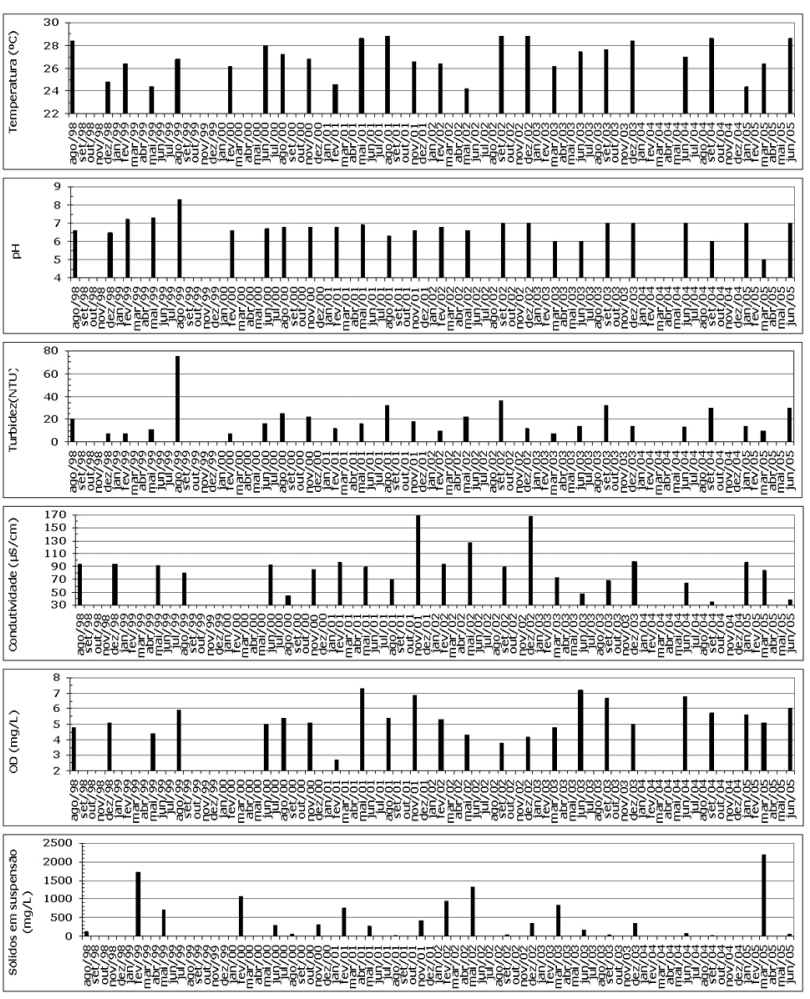

Figura 7 - Série temporal das variáveis de qualidade de água em Seringal da Caridade resultados obtidos somente para o Seringal da Caridade, porém os mesmos gráficos foram feitos para cada localidade.

\section{DISCUSSÃO}

\section{SERINGAL DA CARIDADE}

Em Seringal da Caridade, ao contrário de outras localidades, a temperatura sempre foi inferior a $30^{\circ} \mathrm{C} . \mathrm{O} \mathrm{pH}$ neste local manteve-se entre 6 e 7 e apenas uma vez atingiu valor 5,0 (Fev/05). A data deste menor valor pode ser um indicativo de relação com o aumento da precipitação em fevereiro de 2005, pois coincide com a maior precipitação registrada no período observado $(436 \mathrm{~mm})$ e com a do maior valor de sólidos suspensos, que é a variável que mais se alterou no período chuvoso. Ao contrário do que se esperava, a turbidez foi consideravelmente baixa para essa data. Segundo Arcova e Cicco (1999), com o aumento da precipitação e conseqüente aumento dos sólidos em suspensão, ocorrem picos nos valores de turbidez nos meses chuvosos, pois eles impedem o feixe de luz de penetrar na água.

Os sólidos em suspensão de Seringal da Caridade foram mais altos em comparação com as demais estaçôes de coleta, com destaque para Fevereiro a Maio. De 1999 a 2001, o mês de fevereiro sempre atingiu os maiores índices desta variável. O ponto de coleta de Seringal da Caridade está localizado próximo ao perímetro urbano de Boca do Acre (AC), área de elevada ação antrópica. Desta forma, é possível que a alta concentração de sólidos em suspensão nas águas do Rio Purus seja indicativo de degradação ambiental em áreas próximas ao local de amostragem. 
A condutividade também apresentou valores elevados em Seringal da Caridade, principalmente nos meses da estação chuvosa. Sua média mensal foi a maior encontrada entre as demais localidades. Harding et al. (2006) também encontrou condutividade significativamente alta em áreas de agricultura próximas a remanescentes florestais da Nova Zelândia. Esteves (1998) diz que em regiōes tropicais, os valores de condutividade nos ambientes aquáticos estão mais relacionados com as características geoquímicas e com as condições climáticas (estação de seca e de chuva) da região onde se localizam.

O oxigênio dissolvido apresentou $25 \%$ das amostras com valores abaixo de $5 \mathrm{mg} / \mathrm{L}$, em meses isolados tanto na estação seca como na estação chuvosa, sem apresentar correlação significativa com a precipitação.

\section{SERINGAL DA FORTALEZA}

Em 1998 e 1999, as temperaturas mais altas do ano no Seringal da Fortaleza ocorreram em Agosto (período de seca). Por três anos consecutivos (2001, 2002, 2003) apresentou maior temperatura em Novembro, ou seja, no início do período chuvoso. Apenas uma vez ao longo do período observado (Nov/2002) a temperatura da água atingiu valor superior a $30^{\circ}\left(30,2^{\circ}\right)$.

$\mathrm{O} \mathrm{pH}$ apresentou índices acima de 6,0 em 90\% das amostras. Este resultado é considerado satisfatório, pois a maioria das amostras está dentro dos limites estipulados como ideais segundo as normas da Conama 357/05, que é de 6 a 9 .

Em Novembro de 2001, o índice mais alto de condutividade coincidiu quando a temperatura da água foi mais alta $\left(28,4^{\circ} \mathrm{C}\right)$. Segundo Esteves (1998), a atividade iônica de uma solução é fortemente dependente de sua temperatura (aumenta cerca de $2 \%$ a cada ${ }^{\circ} \mathrm{C}$ ). Em 2002 e 2003 essa variável atingiu seus maiores índices em setembro. Esses resultados indicam que tanto temperatura quanto condutividade elétrica apresentam seus máximos no final da estação seca.

$\mathrm{Na}$ variável Oxigênio dissolvido, $42 \%$ das amostras apresentaram valores abaixo de $5 \mathrm{mg} / \mathrm{L}$, mínimo estipulado pela Resolução do Conama 357/05 para águas de rios como o Purus. Ainda segundo Esteves (1998) "as condições de hipoxia (baixa concentração de oxigênio) ou mesmo anoxia, em lagos tropicais pode causar mortandade de peixes, mesmo em lagos totalmente livres de poluição, como os localizados na região amazônica. Estudos sobre a adaptação dos organismos aquáticos às condiçôes de hipoxia e anoxia em lagos brasileiros foram realizados principalmente com peixes. Em águas amazônicas, encontram-se os melhores exemplos sobre respiração aérea obrigatória ou facultativa em peixes. Este fato está, certamente, relacionado com as frequentes condiçôes de anoxia destes ambientes". A adaptabilidade de certas espécies de peixes encontrados na bacia amazônica pode ser a explicação para o rio Purus apresentar em alguns períodos, baixa quantidade de oxigênio dissolvido, e ainda ser responsável por $40 \%$ do desembarque pesqueiro nos mercados de Manaus. No período analisado, três picos de aumento de sólidos em suspensão ocorreram em Fevereiro (2002, 2003 e 2005), coincidindo com o período de máxima ocorrência de chuvas.

A turbidez manteve baixos valores ao longo do período estudado, apresentou picos de aumento de Agosto e Setembro, ou seja, durante a estação seca. Similarmente ao Seringal da Caridade, os altos valores de turbidez durante a estação seca, foram contrários ao esperado. Em dois anos consecutivos, 2003 e 2004, este parâmetro apresentou baixos valores em todas as estações do ano.

\section{LÁBREA}

Em Lábrea, a temperatura da água manteve-se sempre abaixo dos $30^{\circ} \mathrm{C}$. Segundo Esteves (1998), nos trópicos, variaçōes da intensidade luminosa e da temperatura (acima dos níveis limitantes ao crescimento) são reduzidas entre diferentes estaçōes do ano, mas com grandes variações no decorrer de 24 horas.

$\mathrm{O}$ pH médio do local manteve-se acima de 6 e apenas $13 \%$ das amostras apresentaram valores de 5, o que não é considerado ideal pela Resolução do Conama 357/05. Porém, percebe-se em vários estudos nos rios do Amazonas e de São Paulo, que a tendência dos rios brasileiros é de apresentar $\mathrm{pH}$ ligeiramente ácido, sem causar danos ao ambiente aquático (Maier, 1987; Bueno et al., 2005; Horbe et al., 2005). Gunkel et al. (2000) cita os rios Mujui dos Campos e Muju como típicos rios da Amazônia que apresentam águas ácidas e $\mathrm{pH}$ de 5.1 e 4.7, respectivamente.

A turbidez manteve índices abaixo de 60 NTU sendo que os maiores (menores) valores ocorreram durante a estação seca (chuvosa), como nas demais localidades.

O nível de oxigênio dissolvido, que até o mês de Junho de 2003 apresentava valores inferiores a $4 \mathrm{mg} / \mathrm{l}$, passou a superiores a $6 \mathrm{mg} / \mathrm{l}$ até a última amostragem de 2005 . Esse resultado indica uma sensível melhora desse parâmetro uma vez que o mesmo foi elevado para níveis aceitáveis pela resolução Conama 357/05. Porém, não se percebe correlação desta melhora com outra variável, principalmente com o volume de chuvas. Esteves (1998) diz que dentre as variáveis que apresentam maiores variaçôes diárias, destaca-se o oxigênio dissolvido, devido ao direto envolvimento deste com a fotossíntese e a respiração e/ou decomposição. Estas variações estão diretamente ligadas com o fotoperíodo, a intensidade luminosa e a temperatura, podem, no entanto, outros fatores como os ventos e as chuvas, terem importância eventual. 
Os sólidos em suspensão apresentaram seus maiores valores na estação chuvosa, como observado nas outras localidades, com exceção de uma amostra que apresentou altos índices em Junho de 1999, período de pouca precipitação.

A condutividade que, apresentou de 1998 a 2000 índices praticamente estáveis ao longo do ano, começou no ano de 2001 até 2005 a apresentar variações, com os picos de aumento registrados no fim da estação seca, como também foi observado no Seringal da Fortaleza.

\section{ARUMÃ}

Arumã é a localidade que mais vezes atingiu temperaturas acima de $30^{\circ}$ (Out/98, Jul/02, Out/02 e Nov/03). Segundo Maier (1987), a temperatura da água é determinada pelo aquecimento por raios solares que é diretamente proporcional à área de superfície. Arumã é o ponto de coleta mais à jusante do rio Purus, é o que apresenta maior extensão em largura e, conseqüentemente maior área de superfície em contato com os raios solares.

Os sólidos em suspensão por quatro anos consecutivos (2001, 2002, 2003 e 2004) tiveram seus maiores valores em Janeiro, coincidindo com o pico da estação chuvosa.

$\mathrm{Na}$ estação chuvosa, a turbidez apresentou seus menores valores, enquanto que na seca os maiores valores anuais foram atingidos em Julho de 1999 a 2004. Resultado semelhante também foi encontrado por Horbe et al.(2005) ao estudar o rio Puraquequara, localizado na zona rural leste do município de Manaus.

A condutividade apresentou seu maior valor em Abril/99, porém não se observou nenhuma evidente relação com outra variável.

Arumã apresentou as menores temperaturas e os menores valores de $\mathrm{pH}$ quando comparados com as demais localidades. A queda acentuada do $\mathrm{pH}$ aconteceu em Abril de 2003 e persistiu até o último registro feito em 2005. No Brasil, ecossistemas aquáticos continentais com baixo $\mathrm{pH}$ são encontrados na região de terra firme da Amazônia central, onde corpos d'água chegam a apresentar valores entre 4,0 e
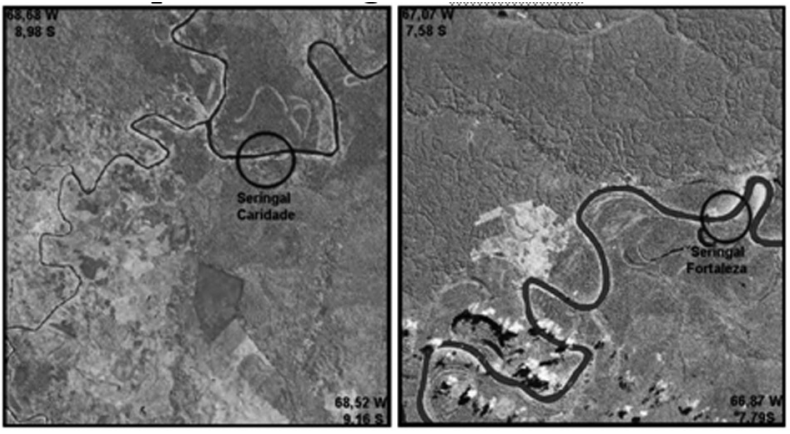

5,5. Isto é um indício da ausência de substâncias tamponadoras (bicarbonato e carbonato) em solução (Esteves, 1998). A diminuição dos valores de $\mathrm{pH}$ foi seguida de um aumento da temperatura da água.

Todos os demais valores das variáveis analisadas, com exceção do oxigênio dissolvido que se manteve igual, apresentaram valores médios superiores aos seus pares obtidos nas demais localidades. Isso é um indicativo muito forte de que a qualidade da água do Rio Purus em Arumã é melhor do que aquela encontrada a montante deste trecho.

\section{USO DO SOLO}

Os resultados encontrados nessa pesquisa sugerem que a localidade Seringal da Caridade tem a pior qualidade de água, enquanto o Seringal do Arumã a melhor. O uso do solo e o regime de precipitaçáo da área estudada parecem ser os principais agentes que interferem na qualidade da água do Rio Purus. Plamondona et al. (1991) em seu trabalho em regiōes de Oxapampa no Peru observou um significativo aumento na temperatura da água e modificações nas concentraçôes de $\mathrm{pH}$ e oxigênio dissolvido em locais onde ocorreu remoção de floresta. A figura 8 mostra a localização dos pontos de coleta de água sobre a área de estudo a partir de imagens Landsat/ TM.

Percebe-se que Seringal da Caridade está localizado a jusante do município de Boca do Acre onde se visualiza alto grau de antropismo. A conversão de florestas no entorno desse local expóe o solo e facilita o transporte de sedimentos para o rio durante os eventos de chuva. Isto demonstra a contribuição do desmatamento. Estas águas do escoamento superficial são consideradas poluidoras devido a grande quantidade de impurezas e detritos que conduzem provenientes da lavagem dos solos (Tavares, 2005). Os altos valores de sólidos em suspensão encontrados nessa região parece ser resultado direto desse fenômeno. Em direção oposta a isso, Arumã está localizada em uma área onde a alteração da cobertura vegetal é praticamente inexistente, isso facilita a infiltração e percolação da precipitação no solo, o que reflete a boa qualidade da água no local. Segundo Tucci (2002), a cobertura vegetal é

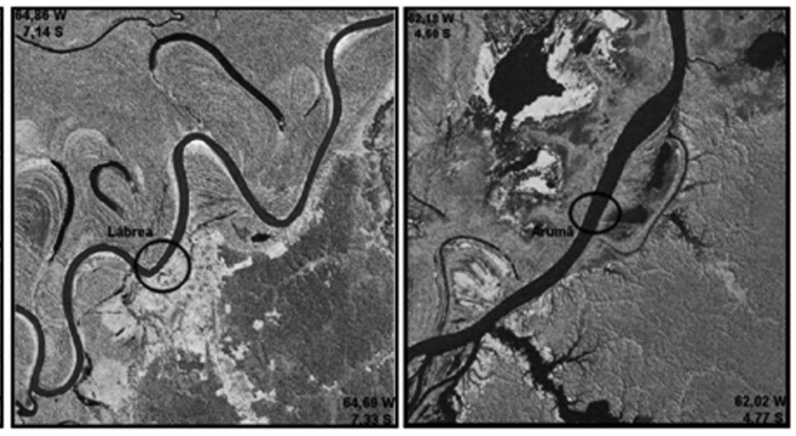

Figura 8 - Cobertura da Terra e uso do solo no entorno dos pontos de amostragem de água 
uma questão importante como interceptação no escoamento das chuvas. Lábrea está localizada em um local onde a ação antrópica é intensa, porém não atinge a magnitude daquela encontrada em Boca do Acre. Isso pode ser a explicação dos valores desse local serem superiores àqueles encontrados em Arumã, porém inferiores ao do Seringal da Caridade. Seringal da Fortaleza também localiza-se em uma área cuja ação antrópica é percebida, mas não tão intensa. Os resultados das variáveis físico-químicas analisadas assemelham-se com seus pares de Lábrea.

\section{CONCLUSÕES}

A turbidez registrou seus maiores índices na estação seca, em todas as localidades estudadas, discordando de algumas pesquisas que apontam o aumento desse parâmetro como conseqüência do aumento de sólidos em suspensão, registrado em todas as localidades no período chuvoso. Essa discordância pode ser atribuída ao tamanho e natureza das partículas que afetam diretamente o valor da turbidez (Pádua e Bernardo, 2001; Teixeira e Senhorelo, 2000). Em todas as localidades estudadas, o $\mathrm{pH}$ apresentou números abaixo ou no limite inferior dos padróes de qualidade para corpos d'água recomendados pelo Conama 357/05, que é de 6 a 9. Poucas vezes ultrapassou o limite inferior, sem demonstrar significativa alcalinidade. Porém, isto não deve ser encarado como desqualificação do corpo d'água, mas sim como necessidade de adequação da Resolução da Conama, visto que estudos anteriores comentaram que, em rios brasileiros, o $\mathrm{pH}$ varia de neutro a ácido, e que existem rios na Amazônia com pH baixo, atingindo a neutralidade praticamente em águas marinhas (Maier, 1987). Esta acidez parece ser uma característica própria dos rios da Amazônia e aparentemente, não influenciam negativamente na qualidade das águas, pois o rio Purus, é a principal fonte de pesca que abastece os mercados de Manaus. Pizella (2006) sugere aos órgãos responsáveis por estas normas de enquadramento, a adoção de parâmetros e padróes de qualidade, adequando-os às especificidades locais e a condiçôes de referência para análise da situação ambiental, ao invés de considerar a qualidade hídrica em função dos usos, permitindo a detecção do real estado do ecossistema, além de possibilitar parâmetros para a melhoria de sua qualidade. Segundo Tucci (2002), a legislação brasileira enfoca o controle de qualidade da água baseada em usos da água e correspondente limite aceitável de poluição. Como esses limites foram estabelecidos normalmente em países de condições ambientais diferentes do nosso, podem ocorrer avaliaçôes equivocadas. Este autor ainda diz que, em relação à preservação da vida aquática, poderão existir locais, onde espécies adaptadas a um meio natural não sofrem negativamente a concentração de determinado elemento, que em outro local pode lhe ser tóxica.
Apesar de preliminares, os resultados obtidos nessa pesquisa mostram que a precipitação parece ser o principal agente influenciador da qualidade da água do rio Purus, uma vez que foi observado que as principais variáveis monitoradas se correlacionaram significativamente com o regime de chuvas do local. A sazonalidade do ciclo anual de precipitação em todas as localidades estudadas indica maior possibilidade de influência na qualidade da água em determinadas épocas do ano. Neste estudo não foi avaliado o impacto de atividades antrópicas na qualidade da água monitorada, porém no Seringal da Caridade, situado no ponto mais a montante do trecho estudado, parece haver influência direta da interferência humana. Neste local sob influência da área urbana do município de Boca do Acre (AC), os valores de turbidez e sólidos em suspensão apresentaram-se muito acima dos demais analisados nas outras estações. Em Arumã, situada no ponto mais a jusante do trecho estudado, os parâmetros avaliadores apresentaram os melhores índices quando comparados com os demais. Este local, que está situado próximo á foz do rio Purus, tem a vantagem de receber águas mais diluídas e com escoamento mais rápido causado pelo aumento no volume de água, e não apresenta sinais de degradação ambiental em seu entorno.

Pelos resultados obtidos nessa pesquisa, é possível verificar que eventuais impactos na qualidade da água causados por atividades humanas, principalmente em locais próximos a perímetros urbanos, parece ter abrangência somente em escala local.

\section{AGRADECIMENTOS}

Este trabalho foi desenvolvido com recursos do $\mathrm{CNPq}$ Processo nr. 104201/2006-1 (NV).

\section{BIBLIOGRAFIA CITADA}

Angelis, C.F.; McGregor, G.R.; Kidd, C. 2004. A 3 year climatology of rainfall characteristics over tropical and subtropical South America based on Tropical Rainfall Measuring Mission Precipitation Radar data. International Journal of Climatology, 24: $385-399$.

Arcova, F.C.S.; Cicco, V. 1999. Qualidade da água de microbacias com diferentes usos do solo na região de Cunha, estado de São Paulo. Scientia Forestalis, (56): 125-134.

Bueno, L.F.; Galbiatti, J.A.; Borges, M.J. 2005. Monitoramento de variáveis de qualidade da água do Horto Ouro Verde - Conchal SP. Eng. Agrícola, 25(3): 742-748.

CETESB - Companhia Estadual Técnica de Saneamento Básico e Defesa do meio Ambiente, 2006. Variáveis de qualidade das águas, (http://www.cetesb.sp.gov.br). Acesso: 08/11/2006.

CONAMA - Conselho Nacional do Meio Ambiente, 2006. Resolução no357 de 17 de março de 2005, (http://www.mma. gov.br/conama). Acesso: 08/11/2006. 
Carvalho, A.R.; Schlittler, F.H.M.; Tornisielo, V.L. 2000. Relações da atividade agropecuária com parâmetros físicos químicos da água. Química Nova, 23(5): 618-622.

Esteves, F.A. 1998. Fundamentos de Limnologia. Interciência, Rio de Janeiro. 602 pp.

Figueroa, S.N.; Nobre, C.A. 1989. Precipitation distribution over Central and Western tropical South America. Climanalise, 5: 36-45.

Gunkel, G.; Lange, U.; Walde, D.; Rosa, J.W.C. 2000. Environmental Impact of an Amazon Reservoir, Curuá-Una /Pará: Limnological Aspects. German-Brazilian Workshop on Neotropical Ecosystems - Achievements and Prospects of Cooperative Research. Hamburg. Session 3: 511-516.

Harding, J.S.; Claassen, K.; Evers, N. 2006. Can forest fragments reset physical and water quality conditions in agricultural catchments and act as refugia for forest stream invertebrates? Hydrobiologia. 568: 391-402.

Horbe, A.M.C.; Gomes, I.L.F.; Miranda, S.F.; Silva, M.S.R. 2005. Contribuição à hidroquímica de drenagens no Município de Manaus - AM. Acta Amazonica, 35(2): 119-124.

Maier, M.H. 1987. Ecologia da bacia do rio Jacaré Pepira (47055' $48^{\circ} 55^{\prime} \mathrm{W} ; 22^{\circ} 30^{\prime}-21^{\circ} 55^{\prime} \mathrm{S}$ - Brasil): qualidade da água do rio principal. Ciência e Cultura, 39(2): 164-185.
Pádua, V.L; Bernardo, L.D. 2001. Comparação entre Turbidez e distribuição de tamanhos de partículas. XXI Congresso Brasileiro de Engenharia Sanitária e Ambiental, I - 044: 1-10.

Pizella, D.G. 2006. Análise da sustentabilidade ambiental do sistema de classificação das águas doces superficiais. Dissertação de Mestrado, Escola de Engenharia de São Carlos-EESC/Universidade de São Paulo-USP, São Carlos, São Paulo. 159pp.

Plamondona, A.P.; Ruizb, R.A.; Moralesc, C.F.; Gonzalezd, M.C. 1991. Influence of protection forest on soil and water conservation (Oxapampa, Peru). Elsevier Science Publishers B.V., 38:227238.

Tavares, A.R. 2005. Monitoramento da qualidade das águas do rio Paraíba do Sul e diagnóstico de conservação. Dissertação de Mestrado, Instituto Tecnológico de Aeronáutica-ITA, São José dos Campos, São Paulo. 176pp.

Teixeira, E.C; Senhorelo, A.P. 2000. Avaliação de correlação entre Turbidez e concentração de Sólidos Suspensos em bacias hidrográficas com uso e ocupação diferenciada. XXVII Congresso Interamericano de Engenharia Sanitária e Ambiental, V - 013: 1-5.

Tucci, C.E.M. 2002. Hidrologia: ciência e aplicação. UFRGS Editora, Porto Alegre. 943 pp.

Recebido em 14/01/2008

Aceito em 16/09/2008 